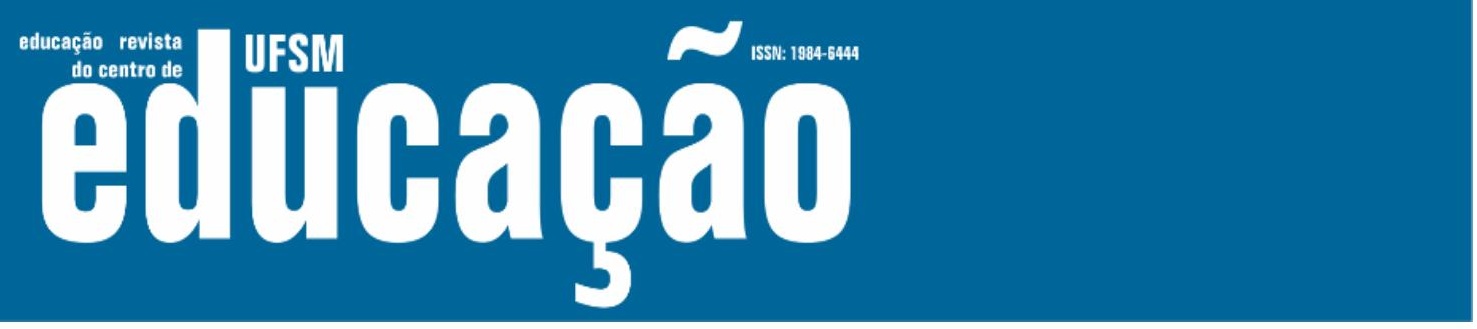

ISSN: 1984-6444 | http://dx.doi.org/10.5902/1984644442481

\title{
Educação e didática no Ensino Fundamental: aprendendo geociências com kits de minerais e rochas
}

\author{
Education and didactics in elementary school: learning geosciences with \\ mineral and rock kits
}

Silas Samuel do Santos Costa

Bacharelando na Universidade Federal do Rio Grande do Norte, Natal, Rio Grande do Norte, Brasil. geomin.silas@hotmail.com - https://orcid.org/0000-0002-0314-278X

Narla Sathler de Oliveira Musse

Professora titular do Instituto Federal de Educação, Ciência e Tecnologia do Rio Grande do Norte Campus Natal Central.

narla.musse@ifrn.edu.br - https://orcid.org/0000-0002-6894-2884

Rafael Rabelo Fillippi

Doutorando na Universidade de Coimbra. Coimbra, Portugal.

rafael.fillippi@ifrn.edu.br - https://orcid.org/0000-0002-5831-6484

Lucas dos Santos Costa

Doutorando na Universidade de São Paulo. São Paulo, São Paulo, Brasil.

adm.lucassantos@hotmail.com - https://orcid.org/0000-0002-0979-3567

Mayara Maria Mendes da Silva

Licencianda na Universidade Federal do Rio Grande do Norte, Natal, Rio Grande do Norte, Brasil. mayaramendes.edu@gmail.com - https://orcid.org/0000-0002-3505-6464

Recebido em 23 de julho de 2020

Aprovado em 17 de agosto de 2020

Publicado em 10 de março de 2021

\section{RESUMO}

Este artigo apresenta uma ferramenta didática para o ensino de geociências no Ensino Fundamental, difundindo o conhecimento sobre o patrimônio geológico do Rio Grande do Norte (RN) e auxiliando os professores na construção de aulas práticas-teóricas sobre minerais, rochas e estudo do planeta Terra. O trabalho está baseado em três processos: elaboração, aplicação e análise sobre os kits. Os kits foram elaborados em cinco etapas: levantamento bibliográfico; coleta de amostras representativas da geologia do $\mathrm{RN}$; caracterização e documentação dos minerais e rochas; montagem dos kits. A aplicação foi realizada em quatro etapas: visita guiada na exposição do "Museu de Minérios do RN"; oficina prático-expositiva com os kits; aplicação de teste para verificação da aprendizagem; e, entrega dos kits às escolas. A análise foi realizada mediante três técnicas de análise estatística para avaliar a aprendizagem e a descrição do caso estudado. Os 248 questionários aplicados 


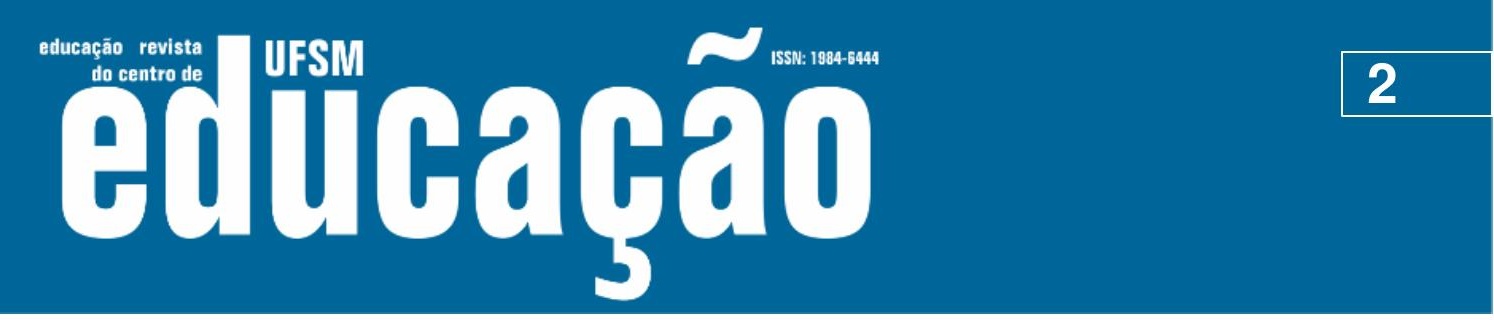

ISSN: 1984-6444 | http://dx.doi.org/10.5902/1984644442481

revelaram o maior índice de acerto para questões que associavam minerais e rochas com aplicações cotidianas e tinham relação com o que foi apresentado nos kits, já questões respondidas com maior aleatoriedade contavam com conteúdos sobre gênese de rochas e aplicação industrial de minerais. A participação e interação são pontos positivos vistos na aplicação dos kits, os quais podem ser utilizados em sala de aula como material didático para aprimoramento de aprendizagem, dando suporte para conteúdos previstos na Base Nacional Comum Curricular (BNCC).

Palavras-chave: Geociências; Kits; Minerais; Rochas.

\section{ABSTRACT}

This article presents a didactic tool for teaching geosciences in elementary school, spreading knowledge about the geological heritage of Rio Grande do Norte (RN) and assisting teachers in the construction of practical-theoretical classes on minerals, rocks and the study of planet Earth. The work is based on three processes: elaboration, application and analysis on the kits. The kits were developed in five stages: bibliographic survey; collection of representative samples of the RN's geology; characterization and documentation of minerals and rocks; assembling the kits. The application was carried out in four stages: guided tour of the exhibition of the "Museu de Minérios do RN"; practical-exhibition workshop with kits; test application for verification of learning; and, delivery of kits to schools. The analysis was carried out using three statistical analysis techniques to assess learning and the description of the case studied. The 248 questionnaires applied revealed the highest rate of correctness for questions that associated minerals and rocks with everyday applications and were related to what was presented in the kits, since questions answered with greater randomness had contents on rock genesis and industrial application of minerals. The participation and interaction are positive points seen in the application of the kits, which can be used in the classroom as didactic material for learning improvement, providing support for contents provided for in the Base Nacional Comum Curricular (BNCC) [the Curricular Common National Base].

Keywords: Geosciences; Kits; Minerals; Rocks.

\section{Introdução}

Nas séries iniciais, do Ensino Fundamental (EF), os alunos começam a desenvolver seus conhecimentos de maneira organizada, nesse cenário, é possível identificar que as ciências da Terra são de extrema importância (COMPIANI, 2005). No caso específico do currículo de ciências, Carneiro, Toledo e Almeida (2004) 


\section{U usm

ISSN: 1984-6444 | http://dx.doi.org/10.5902/1984644442481

diversos nas regiões do Seridó Potiguar, Mato Grande, Vale Assú e Litoral Norte (frentes de lavra, pilhas de rejeito, corte de estradas, falésias e lajedos), contendo: conglomerados da Formação Barreiras (rocha sedimentar paleógena); arenitos da Formação Açu (rocha sedimentar siliciclástica cretácica); calcários da Formação Jandaíra (rocha sedimentar carbonática cretácica); pertencentes à Bacia Potiguar; gnaisses e xistos do Grupo Seridó e Complexo Caicó (rochas metamórficas neoproterozóicas e paleoproterozóicas), granitóides e pegmatitos de suítes ediacaranas (rochas ígneas plutônicas do Neoproterozóico ao Cambriano), inseridos no embasamento cristalino do Domínio Rio Grande do Norte, como se pode ver na Figura 1, todas essas litologias caracterizam fortemente a geologia do estado do RN, que, por sua vez, possuem textos-base como Angelim (2006) e Oliveira e Nascimento (2019). Sendo as litologias compostas por minerais essenciais ou principais como colocam Leinz e Amaral (1989) e Teixeira et al. (2003), obras clássicas de geologia geral, como feldspatos, quartzos, piroxênios e anfibólios, micas, carbonatos e granadas. 


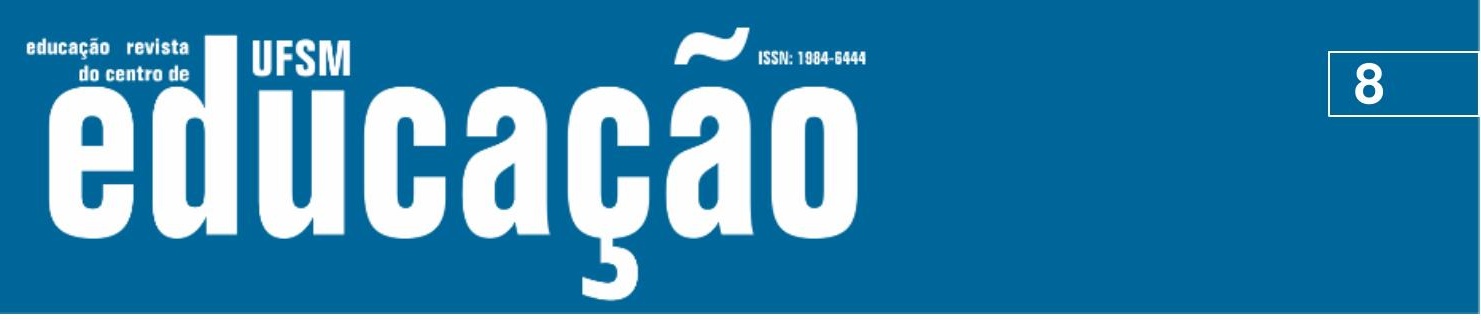

ISSN: 1984-6444 | http://dx.doi.org/10.5902/1984644442481

Figura 1 - Mapa litológico simplificado do Rio Grande do Norte.

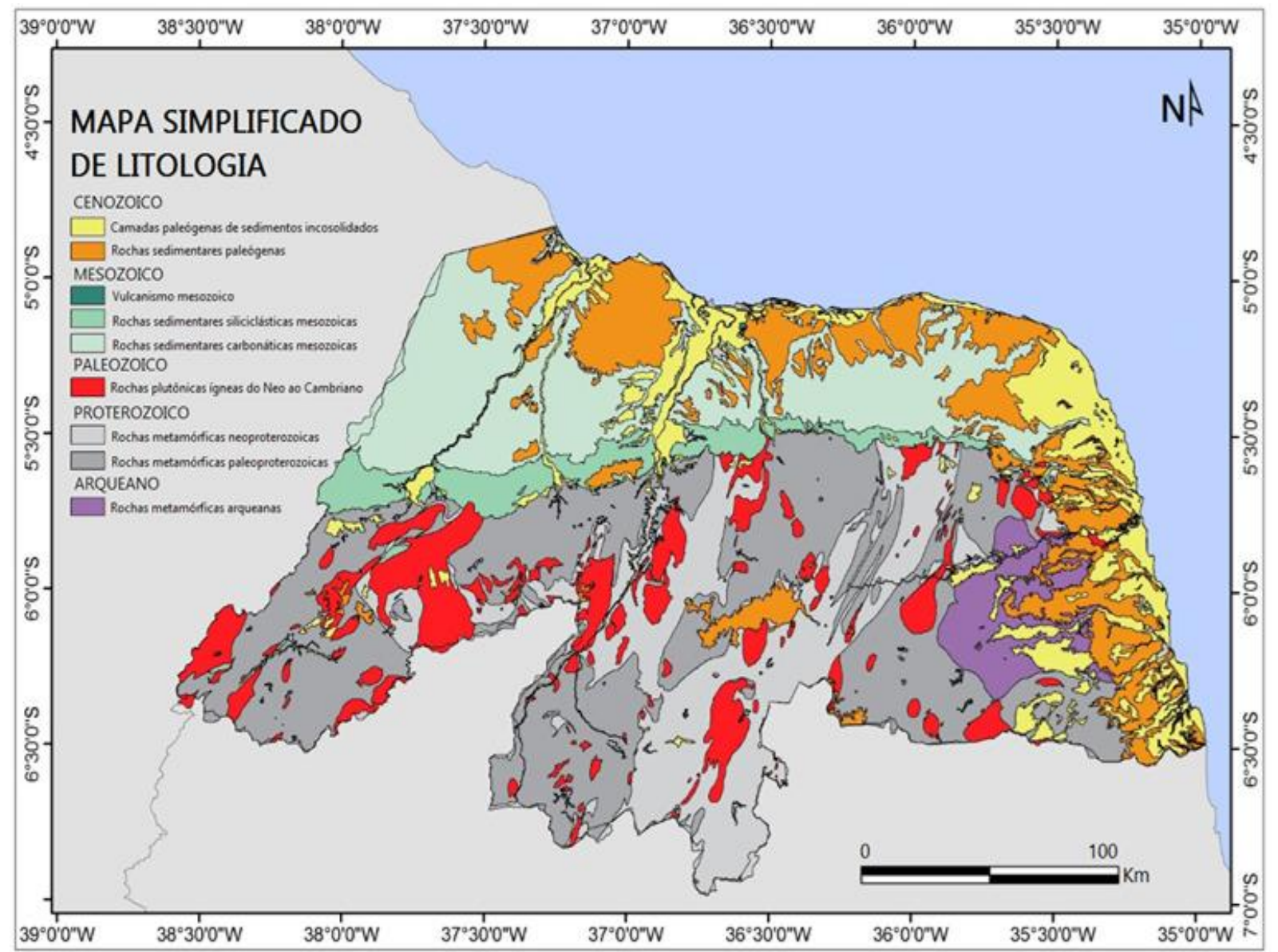

Fonte: Adaptado de Oliveira e Nascimento (2019).

O próximo passo (terceira etapa) na realização do projeto foi direcionado para a produção dos kits, havendo o selecionamento, descrição e documentação das amostras. Quanto à disposição das amostras na caixa, cada uma delas conteria uma rocha referente a cada tipologia (ígnea, metamórfica e sedimentar) e sua respectiva descrição petrográfica básica simplificada (nome da rocha, minerais constituintes, cor e peso). A caixa para os kits de minerais e rochas foi projetada, inicialmente, tomando como base o modelo de kits didáticos visto em Béramo et al. (2017) e depois foi modelado usando o software SketchUp Pro 2017®, como se observa no modelo da Figura 2, e - em seguida, colocado para execução, trabalhado em material de madeira compensada, tendo 9 compartimentos diferentes, para colocação de 3 tipos de rochas e 6 amostras de diferentes minerais formadores de 


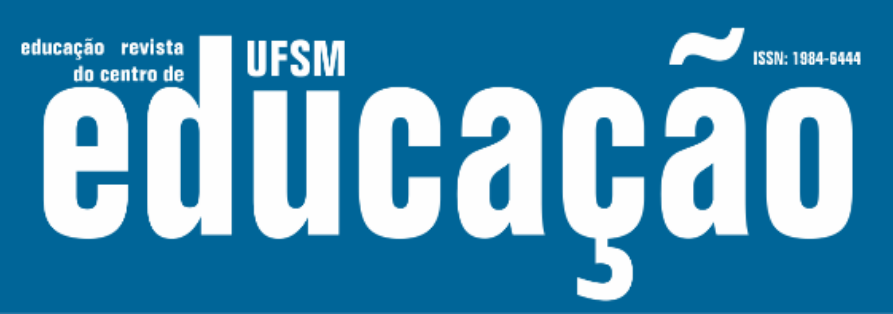

ISSN: 1984-6444 | http://dx.doi.org/10.5902/1984644442481

rochas.

Figura 2 - Modelo digital 3D da caixa dos kits de minerais e rochas.

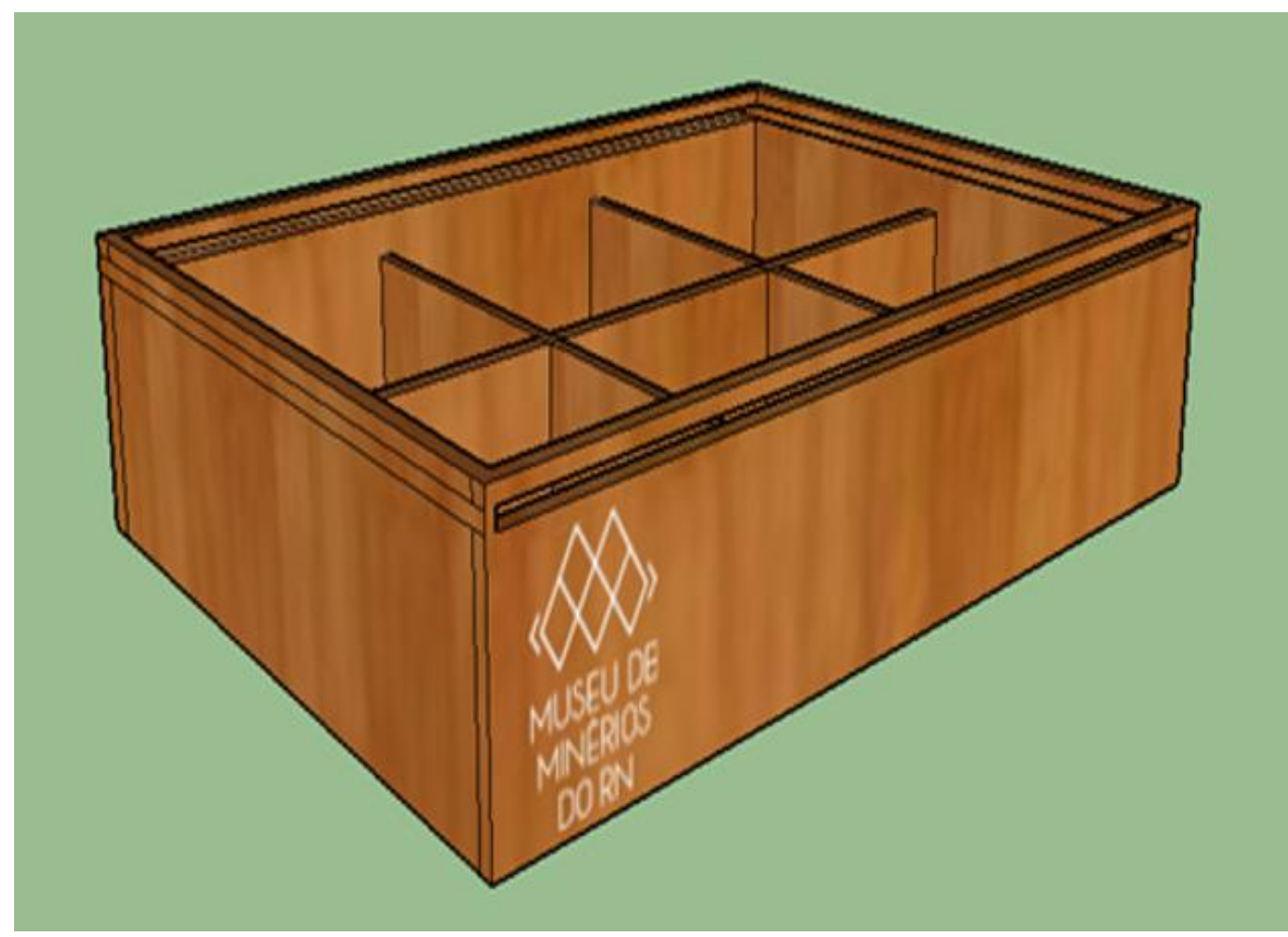

Fonte: Os autores, 2018.

A descrição do conteúdo da caixa foi impressa em um folheto avulso à caixa. $\mathrm{Na}$ Figura 3, vê-se o detalhamento conceitual das amostras e suas formas de ocorrência no RN. 


\section{ussm \\ ISSN: 1984-6444

Figura 3 - Modelo de folheto explicativo anexo aos kits de minerais e rochas.

\begin{tabular}{|c|c|c|}
\hline 1 Calcário & $\begin{array}{l}\text { Rocha sedimentar de origem } \\
\text { marinha, com calcita na minera- } \\
\text { logia, que efervesce } \\
\text { em contato com ácido cloridrico }\end{array}$ & $\begin{array}{l}\text { No norte do estado, numa bacia sedimentar, } \\
\text { chamada Bacia Potiguar, na Formação Jandaira, } \\
\text { marca o avanço do nivel do mar do final do } \\
\text { Cretáceo }\end{array}$ \\
\hline 2 Xisto & $\begin{array}{l}\text { Rocha metamórfica de origem } \\
\text { sedimentar, conteúdo argiloso que } \\
\text { sofreu mudanças devido às altas } \\
\text { condiçőes de pressão e temperatura }\end{array}$ & $\begin{array}{l}\text { Em faixas com direção NE-SW, } \\
\text { da Formação Seridó, constituindo um } \\
\text { grupo de rochas metassedimenta- } \\
\text { res, de idade neoproterozoica, } \\
\text { que compõe antiga bacia sedimentar }\end{array}$ \\
\hline 3 Granito & $\begin{array}{l}\text { Rocha ignea intrusiva originada } \\
\text { por magmas que foram gerados na } \\
\text { crosta, em sua mineralogia contém } \\
\text { quartzo, mica e feldspato }\end{array}$ & $\begin{array}{l}\text { Dispostos em direção NE-SW, no centro-sul } \\
\text { do estado, em corpos grandes chamados } \\
\text { batólitos, são classificados conforme sua } \\
\text { quimica em suites, têm idade neoproterozoica }\end{array}$ \\
\hline 4 Mica & $\begin{array}{l}\text { Mineral do grupo dos silicatos, se } \\
\text { desplaca como folhas, tem brilho } \\
\text { metálico e cor que pode ser preta, } \\
\text { cinza, verde e roxa }\end{array}$ & $\begin{array}{l}\text { Está presente em diversos tipos de } \\
\text { rochas, mais comumente em granitóides, xistos } \\
\text { e quartzitos, que por sua vez estão dispostos } \\
\text { no centro-sul do estado }\end{array}$ \\
\hline 5 Plagioclásio & $\begin{array}{l}\text { Mineral do grupo dos silicatos, branco, } \\
\text { lembra uma tábua, não passa luz } \\
\text { através dele, possui arestas e brilho } \\
\text { de resina }\end{array}$ & $\begin{array}{l}\text { Ocorre em todos os tipos de rochas, nas } \\
\text { igneas ocorre em granitóides, gabros e diabá- } \\
\text { sios, nas metamórficas, em gnaisses e nas se- } \\
\text { dimentares como detritos em arenitos }\end{array}$ \\
\hline 6 Quartzo & $\begin{array}{l}\text { Mineral do grupo dos silicatos, transpa- } \\
\text { rente, de brilho vitreo, se quebra em } \\
\text { formato de concha e consegue riscar } \\
\text { o vidro }\end{array}$ & $\begin{array}{l}\text { Nas ígneas ocorre em granitóides, nas meta- } \\
\text { mórficas, em quartzitos, xistos e gnaisses e nas } \\
\text { sedimentares em cherts, conglomerados e } \\
\text { arenitos }\end{array}$ \\
\hline 7 Granada & $\begin{array}{l}\text { Mineral do grupo dos silicatos, lembra } \\
\text { uma bola, tem doze faces, coloração } \\
\text { avermelhada, tem brilho vitreo é é } \\
\text { translúcido }\end{array}$ & $\begin{array}{l}\text { Ocorre principalmente em rochas metamór- } \\
\text { ficas, como xistos e calciossilicáticas, do Grupo } \\
\text { Seridó, e granitóides das suites neoprotero- } \\
\text { zoicas }\end{array}$ \\
\hline 8 Calcita & $\begin{array}{l}\text { Mineral carbonático, transparente, } \\
\text { por vezes em formas romboédrica lo- } \\
\text { sangular e prismática, reage com ácido } \\
\text { clorídrico produzindo bolhas de gás } \\
\text { carbônico }\end{array}$ & $\begin{array}{l}\text { Nas sedimentares está na parte norte do } \\
\text { RN, na Formação Jandaira, e em rochas } \\
\text { metamórficas calciossilicáticas da } \\
\text { Formação Jucurutu, sul do estado do RN }\end{array}$ \\
\hline 9 Berilo & $\begin{array}{l}\text { Mineral do grupo dos silicatos, em for- } \\
\text { mato de hexágono perfeito, de colora- } \\
\text { ção verde, translúcido, consegue riscar } \\
\text { o quartzo e o vidro, sua variedade } \\
\text { verde é a esmeralda, enquanto que a } \\
\text { azul é a água marinha }\end{array}$ & $\begin{array}{l}\text { Principalmente em granitóides neoprote- } \\
\text { rozoicos, mas também na variedade } \\
\text { esmeralda em rochas metamórficas cha- } \\
\text { madas anfibolitos, no oeste e sul do RN }\end{array}$ \\
\hline
\end{tabular}

Fonte: Os autores, 2018.

A quarta etapa foi fundamental. Cabendo destacar que o projeto utiliza os ambientes disponibilizados pelo MMRN, como, por exemplo, a exposição permanente do museu, onde eram feitos guiamentos sobre minerais formadores de rochas e os tipos de rochas existentes no estado do $\mathrm{RN}$ - fundamentais no entendimento e na percepção visual dos bens minerais, e os espaços de auditórios e 


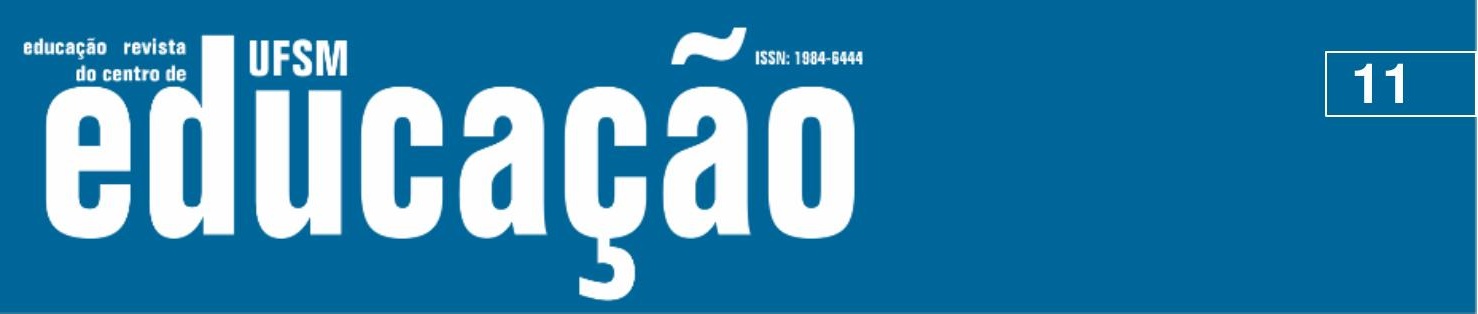

ISSN: 1984-6444 | http://dx.doi.org/10.5902/1984644442481

salões, importantes para a execução das aulas expositivas e apresentação das amostras dos kits, que funcionava como espécie de oficina, que por sua vez, ao final de sua aplicação contava com o instrumento avaliativo tipo questionário misto.

É válido lembrar que, em uma etapa futura (quinta etapa) - na execução do projeto, houve a distribuição dos kits nas escolas de nível fundamental que participaram dessas oficinas, mediante a disponibilidade de recursos para construção desses modelos de kits como o da Figura 4, a meta inicial para o projeto era de 50 kits.

Figura 4 - Modelo-padrão dos kits de minerais e rochas, nas partes "a" e "b" vê-se parte frontal e estrutura da caixa de colocação de minerais e rochas, em "c" as amostras-base para os kits, na fileira de 1 a 3 estão amostras de rochas (c1 calcário, c2 - xisto, c3 - granito) e nas demais amostras de minerais formadores em cristais ou nas rochas (c4 - mica, c5 - plagioclásio, c6 - quartzo, c7 - granada, c8 calcita e c9 - berilo).
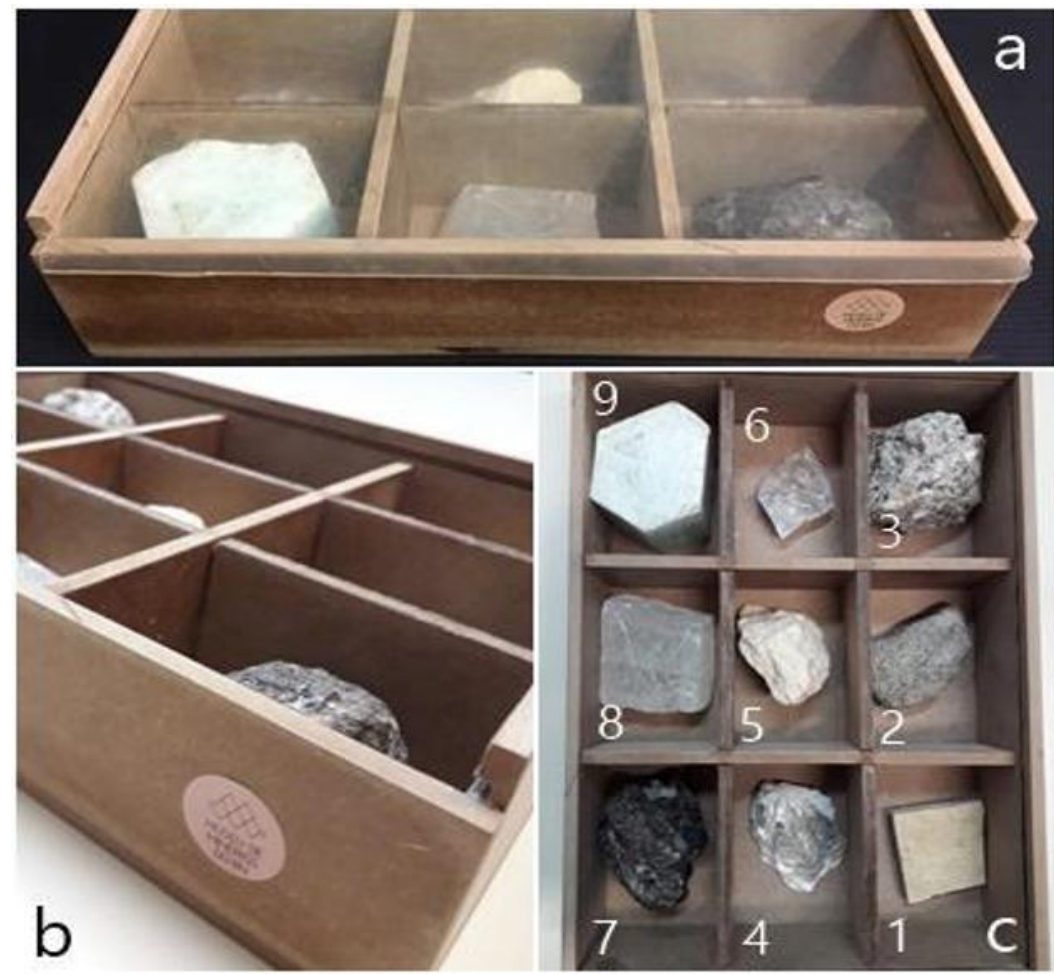

Fonte: Os autores, 2019. 


\section{Eulfoapẫ}

ISSN: 1984-6444 | http://dx.doi.org/10.5902/1984644442481

O instrumento de avaliação de aprendizagem abordava conteúdos de mineralogia (primeira e da sexta à oitava questões), petrografia (segunda à quinta questões) e geomorfologia (nona questão), tais como: minerais formadores de rocha, gênese de rochas sedimentares, tipos de rochas metamórficas, gênese de rochas ígneas, utilização do feldspato, abundância de minerais na crosta terrestre, aplicação industrial dos minerais micáceos e formação de carstes em rochas carbonáticas, respectivamente conforme a ordem das questões. A diversidade de temas confirma como os kits podem ser versáteis em diferentes temas a serem discorridos em sala de aula. Entre as alternativas das questões de múltipla escolha, todas apresentavam pelo menos uma opção correta.

$\mathrm{Na}$ primeira questão, por exemplo, todas as alternativas podem ser consideradas minerais essenciais em diferentes tipos de rochas. $O$ berilo, primeira opção, pode estar presente como mineral essencial em pegmatitos de suítes ediacaranas, enquanto a hematita, segunda alternativa, pode ser essencial em formações ferríferas da Formação Jucurutu, já a granada pode ser essencial em xistos da Formação Seridó e feldspatos, em diversas litologias, é considerado como mineral principal, por esse motivo aparece como alternativa correta (Angelim, 2006).

Na segunda questão, sobre a origem de rochas a partir de sedimentos praiais, as respostas podiam confluir para as alternativas "arenito" e "quartzito", visto que quartzitos tem origem metassedimentar e podem derivar de arenitos praiais. No entanto, em termos genéticos, a resposta "arenito" era mais direta no âmbito de processos do ciclo das rochas.

Nas terceira e quarta questões, foram trabalhadas quais são os exemplos clássicos das litologias do RN, sendo elas "Granito e Basalto", para as rochas ígneas, e "Micaxisto e Gnaisse", para as metamórficas, respectivamente. Nas demais opções, eram colocadas tipologias distintas do solicitado, como forma de contrastar as diferentes classes de rochas e facilitar a escolha das alternativas corretas.

$\mathrm{Na}$ quinta questão, todas as respostas podem ser corretas, uma vez que todos são produtos de emanação vulcânica, "areia" e "pedra" podem dar origem às rochas piroclásticas e a "água" é um importante material no efeito hidrotermal do 


\section{Aillbapẫ

ISSN: 1984-6444 | http://dx.doi.org/10.5902/1984644442481

$$
\chi_{k}^{2}=\sum_{i=1}^{9} \sum_{j=1}^{4} \frac{\left(O_{i j}-E_{i j}\right)^{2}}{E_{i j}}
$$

$\mathrm{Na}$ comparação da distribuição de valores observados da matriz $O_{i j}$, em relação a uma distribuição de valores hipotética da matriz $E_{i j}$, a primeira é composta pela frequência de dados coletados de acordo com questionário estruturado com nove questões fechadas $(i=9)$, cada uma com quatro possibilidades de respostas $(j=4)$; enquanto a segunda é composta pela frequência da esperada respondida de maneira aleatória em cada opção $j$ para cada questão $i$; ainda assim a distribuição está sujeita a $k$ graus de liberdade (FÁVERO; BELFIORE, 2017), nesse caso $k=$ 24.

Em relação à organização dos dados presentes nos questionários, após a verificação da distribuição de frequência de cada uma das quatro alternativas ( $a, b$, c, d), esses dados foram dicotomizados em duas possibilidades: "correta", codificado como 1, e "errado", codificado como 0.

As tabelas de contingência do coeficiente Phi $(\phi)$ foram organizadas com a quantidade de respostas certas na primeira coluna 1, enquanto a quantidade de respostas erradas foi contabilizada na segunda coluna 0 ; e, a quantidade total das respostas da primeira questão $x$ foi quantificada na primeira linha, enquanto o total de respostas da segunda questão y foi contabilizada na segunda linha.

A quantidade de respostas corretas da variável $x$ é representada pelo elemento $x_{1}$, enquanto a quantidade de respostas erradas é representada pelo elemento $x_{0}$. A quantidade de respostas corretas da variável $y$ é representada pelo elemento $y_{1}$, enquanto a quantidade de respostas erradas é representada pelo elemento $y_{0}$. Tal qual como exemplificado a seguir:

Tabela 1 - Representações para as respostas.

\begin{tabular}{|c|c|c|}
\hline Variável & Corretas & Erradas \\
\hline$x$ & $x_{1}$ & $x_{0}$ \\
\hline$y$ & $y_{1}$ & $y_{0}$ \\
\hline
\end{tabular}

Fonte: Os autores, 2019. 


\section{Fism

ISSN: 1984-6444 | http://dx.doi.org/10.5902/1984644442481

O coeficiente Phi $(\phi)$ testa a correlação bivariada $\left(\phi_{x ; y}\right)$ entre duas questões dicotômicas, quanto maior seu coeficiente (magnitude), maior é a concentração de respostas em uma das diagonais da matriz dos elementos $x_{0}, x_{1}, y_{0}, y_{1}$ : principal ou secundária. Quando a correlação é positiva $\left(\phi_{x ; y}>0\right)$, há maior concentração na diagonal principal. Quando a correlação é negativa $\left(\phi_{x ; y}<0\right)$, há maior concentração na diagonal secundária. Quando a correlação é próxima de zero $\left(\phi_{x ; y} \approx 0\right)$, há maior concentração de respostas em alguma das colunas $\left(x_{0} \approx y_{0} \vee x_{1} \approx y_{1}\right)$, linhas $\left(x_{0} \approx\right.$ $\left.x_{1} \vee y_{0} \approx y_{1}\right)$ ou distribuição uniforme entre as células $\left(x_{0} \approx x_{1} \approx y_{0} \approx y_{1}\right)$. coeficiente Phi $(\phi)$ é definido como:

$$
\phi_{x ; y}=\frac{\left(x_{1} \cdot y_{0}\right)-\left(x_{0} \cdot y_{1}\right)}{\sqrt[2]{\left(x_{1}+x_{0}\right) \cdot\left(y_{1}+y_{0}\right) \cdot\left(x_{1}+y_{1}\right) \cdot\left(x_{0}+y_{0}\right)}}
$$

Alguns autores já utilizaram o teste $x^{2}$ para avaliar o nível de aprendizagem, Cordeiro e Silva (2012) relacionaram diversas questões com o desempenho acadêmico/escolar, como o estilo de aprendizagem, gênero, tipo de escola. Capellini et al. (2010), também utilizaram a técnica, agora, para testar a associação entre diversos grupos com diferentes níveis de dificuldade de escrita entre alunos da $1^{1 \underline{a}}$ à $4^{a}$ séries do ensino público. O coeficiente de correlação Phi $(\hat{\phi})$ também pode ser encontrado com base no Qui-Quadrado de Pearson $\left(x^{2}\right)$ quando definido por:

Sendo $n$ o total de estudantes respondentes do instrumento de avaliação de aprendizagem.

$$
\hat{\phi}=\sqrt[2]{\frac{\chi^{2}}{n}}
$$

A diferença dos estimadores $\phi$ e $\hat{\phi}$ reside na possibilidade de interpretação do coeficiente. O primeiro apresenta a magnitude e direção da correlação $(-1<\phi<1)$, enquanto o segundo apresenta somente a magnitude em módulo $(0<\hat{\phi}<1)$. Como o coeficiente de correlação Phi é calculado entre duas variáveis dicotômicas, sua tabela de contingência é sempre definida como quadrada, tendo $i=2$ e $j=2$. Então, todos os $\phi_{x ; y}$ possuem $k=1$. 


\section{工 Wum

ISSN: 1984-6444 | http://dx.doi.org/10.5902/1984644442481

\section{Análise e discussão dos resultados}

\section{Perspectivas de aprendizado com os kits de minerais e rochas}

Diante dos resultados obtidos, por intermédio dos questionários e da execução das oficinas didáticas com os kits de minerais e rochas, associados ao guiamento na exposição permanente no MMRN, observou-se o quanto e de que maneiras a ferramenta dos kits de minerais e rochas podem ser utilizadas para a introdução aos temas de Ciências da Terra nas escolas, participantes das atividades desenvolvidas no projeto.

Assim como ressalta Teasdale, Marcum e Heaston (2008) ao tratarem da teoria construtivista, mencionam a importância de atividades práticas com minerais e rochas em todos os níveis de ensino. As oficinas dos kits (Figura 5), de igual modo, revelaram que os alunos - independentemente de suas situações e séries do EF, seja no primeiro ou segundo nível - possuem interesse e habilidade de interagir com as amostras-de-mão, disposição explicada por ser o primeiro contato físico com elementos da geodiversidade. Corroborando com essa argumentação, um dos alunos comentou na última questão do instrumento de avaliação de aprendizagem: "eu aprendi um pouco mais sobre rochas novas e aprendi ainda mais sobre as rochas que já tinha visto em sala de aula". 


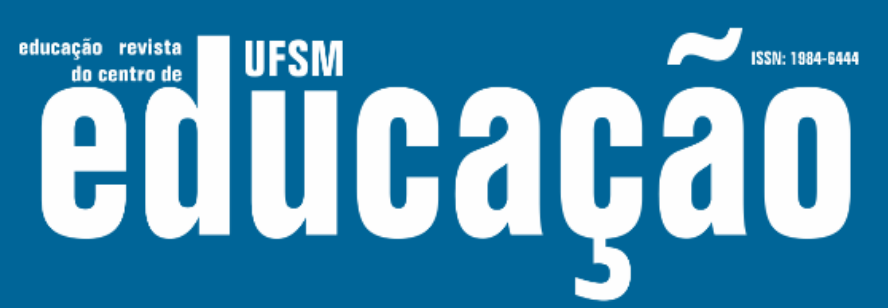

ISSN: 1984-6444 | http://dx.doi.org/10.5902/1984644442481

Figura 5 - Oficinas com as escolas participantes do projeto. Em "a" e "b" vê-se parte expositiva da atividade. Em "c" e "e" o contato dos alunos com as amostras dos kits.

Em "d" a aplicação dos questionários.

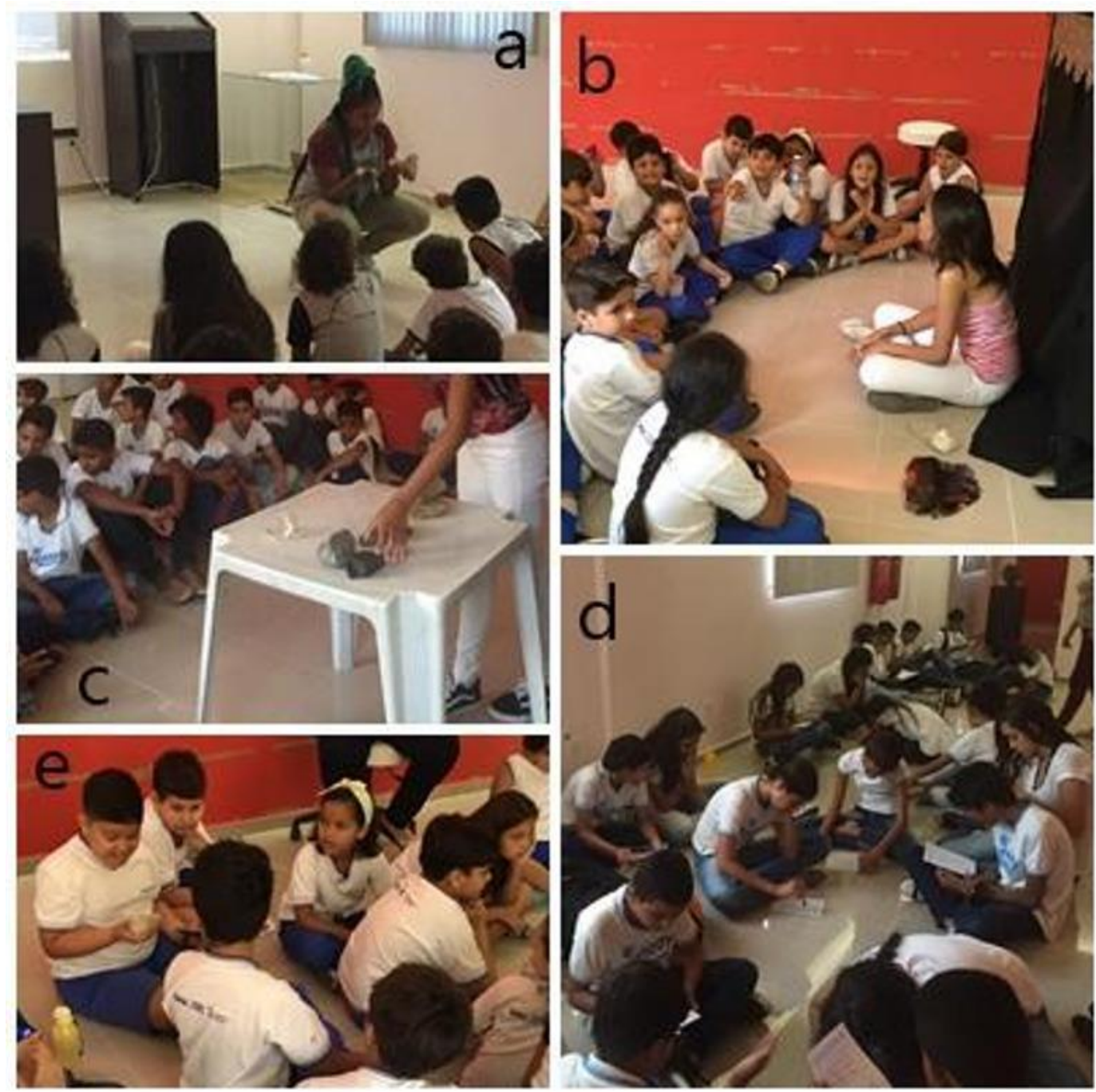

Fonte: Os autores, 2019.

Perguntas tais quais "Como eu acho esse mineral?" e "Serve pra quê?", afirmativas como "Eu já vi esse mineral em um desenho animado ou no Minecraft@" e expressões faciais (Figura 5b, 5c e 5e) são exemplos que revelam o entusiasmo com diferentes materiais remetentes aos objetos do cotidiano, ou, ainda, jogos e conteúdos audiovisuais, ativadores de curiosidade sobre os temas de geociências.

Os alunos demonstraram perplexidade ao visualizarem: o comportamento plástico da mica, a forma euédrica hexagonal do berilo e o brilho sedoso da gipsita, que remete a uma barra de sabão, por exemplo. $O$ interesse pelas propriedades das 


\section{تilfoarẫ}

ISSN: 1984-6444 | http://dx.doi.org/10.5902/1984644442481

rochas é evidenciado nas falas dos estudantes, "eu aprendi várias coisas sobre as rochas e os minerais, a rocha que eu mais gostei foi o calcário, porque ela faz várias espumas e é muito legal", a reação química da rocha carbonática com o ácido clorídrico incita a curiosidade pela liberação de bolhas de gás carbônico.

Algumas falas dos alunos ilustram como suas percepções e aprendizados estão intimamente conectados com sua realidade cotidiana. Discursos, como: "eu aprendi que a areia pode se transformar em várias coisas, como uma rocha, aprendi como fazer o sal e de onde ele vem, aprendi como é feita a panela e como é feita a maquiagem", mostram objetos e elementos da geodiversidade que estão no cotidiano, também é perceptível um tom de surpresa nas diversas junções "mineral e objeto".

Outras respostas também ilustram a nova percepção da inserção dos minerais no cotidiano dos alunos: "aprendi sobre as rochas, os cristais, como eles são usados, para onde eles vão e de onde eles vem" e "eu aprendi que as rochas e os minerais são de grande importância para economia, sociedade e história do Brasil", e, ainda, ressaltam a importância histórica dos recursos minerais para o desenvolvimento socioeconômico da nação, o que relembra a necessidade de se aprender geociências para fortalecer um pensamento crítico e politizado, como bem colocam Stewart e Lewis (2017) sobre o desenvolvimento de opiniões a respeito de questões políticas relacionadas à Terra.

As crianças começam a perceber que os minerais e as rochas também fazem parte de seu mundo, e que eles podem estar presentes em diversos materiais de sua vivência, como mencionado por um dos alunos "eu aprendi muita coisa, aprendi que o ouro na rocha existe em pequena quantidade, as camadas para se formar os fósseis e que os minerais estão em todos os lugares", pode-se dar ênfase às várias vezes às quais os fósseis foram citados, menção compreendida pela proximidade dos alunos com as ciências biológicas desde o início do ensino básico. 


\section{Guthaตão

ISSN: 1984-6444 | http://dx.doi.org/10.5902/1984644442481

\section{Um olhar descritivo sobre a avaliação de aprendizagem}

Após a realização da oficina, com a apresentação oral do conteúdo didático e contato com os kits, foi distribuído um questionário para verificação de aprendizagem das ferramentas didáticas. Foram aplicados um total de 248 questionários entre 7 escolas participantes [2 privadas e 5 públicas (4 municipais e 1 estadual)]. A quantidade de questões assinaladas após o preenchimento está descrita na Tabela 1.

Na primeira questão, praticamente metade dos respondentes (51\%) assinalou corretamente a alternativa "feldspato", considerado como um "mineral formador de rocha". $\mathrm{Na}$ segunda questão, $78 \%$ dos respondentes assinalou "arenito", possivelmente pela semelhança do termo que se refere a granulometria "areia" com o nome da rocha sedimentar.

As terceira e quarta questões, com taxas de acertos de $30 \%$ e $29 \%$ respectivamente, possuem um nível de tecnicidade mais elevado, por tentar associar diretamente a nomenclatura das rochas com suas tipologias litológicas. Os termos ígneo e metamórfico são representações de processos naturais desconhecidos, não usuais do cotidiano dos alunos. Ademais, os diversos nomes de rochas, também não usuais, são difíceis de memorizar com apenas uma prática envolvendo a temática.

O padrão de erros nessas duas questões pode ser explicado pela forma aleatória na escolha das alternativas, revelando um possível ponto fraco na sistemática do ensino e na avaliação de aprendizagem. A aleatoriedade no padrão das respostas será avaliada na próxima análise, com o teste $\chi^{2}$.

As quinta e sexta questões apresentam proporções majoritárias de acertos. $\mathrm{Na}$ quinta questão, $88 \%$ optaram pela alternativa "magma", este resultado sugere maior familiaridade com eventos de vulcanismo, algo já presenciado no cotidiano dos alunos em representações cinematográficas, livros ou programas de televisão. $\mathrm{Na}$ sexta questão, $41 \%$ assinalaram a alternativa "porcelanato" como correta, pois durante a exposição do MMRN foi apresentada a associação do mineral feldspato com utensílios domésticos, como xícaras e pratos. 


\section{OF HEM

ISSN: 1984-6444 | http://dx.doi.org/10.5902/1984644442481

A partir dos questionários de verificação de aprendizagem e do teste QuiQuadrado de Pearson, foi possível constatar os padrões aleatórios de resposta. A Tabela 2 apresenta as distâncias $\chi^{2}$ entre as alternativas de respostas, as frequências de respostas registradas e a distribuição aleatória, cálculo baseado na premissa de que ao não saber qual a alternativa correta o indivíduo marca uma opção aleatória de acordo com sua percepção de preferência. Então, as células com maior proximidade de zero possuem maior associação com marcações aleatórias. Os totais por alternativa apresentam o quanto cada opção foi marcada aleatoriamente, a mesma interpretação pode ser realizada para cada questão na coluna "SR".

As questões respondidas corretamente com o menor índice de aleatoriedade foram as questões: 5,2 e 8 , mostrando que os alunos tiveram maior domínio do conteúdo associado a minerais formadores de rocha, utilização do feldspato e a gênese de cavernas, o que pode ser explicado pela presença desses materiais no kit.

As questões 4,3 e 6 foram destaque por apresentar um alto nível de aleatoriedade na seleção da alternativa correta, revelando insegurança nos conteúdos dessas questões. Como discutido anteriormente, as questões 3 e 4 possuem um nível técnico que exigem memorização de terminologias litológicas, tornando os quesitos mais dificultosos.

A média de aleatoriedade das questões de petrografia é 231 , enquanto a média de mineralogia é 131 e geomorfologia é igual a 146. Então, é possível afirmar que o tema com maior frequência de respostas ao acaso é o de mineralogia, seguido por geomorfologia e petrografia. Apesar desse resultado, as questões de petrografia possuem as duas questões com menor e as duas com maior padrão de respostas aleatórias, enquanto as questões de mineralogia possuem níveis de dificuldade mais similares (Ver Tabela 2 - As alternativas em negrito representam as opções corretas e a Soma das respostas - SR). 


\section{Fism

ISSN: 1984-6444 | http://dx.doi.org/10.5902/1984644442481

Tabela 2 - Distâncias $\chi^{2}$ entre as alternativas de resposta dos questionários sobre a atividade didática com os kits de minerais e rochas.

\begin{tabular}{lrrrrr}
\hline \multicolumn{1}{c}{ Questões } & \multicolumn{1}{c}{ A } & \multicolumn{1}{c}{ B } & \multicolumn{1}{c}{ C } & \multicolumn{1}{c}{ D } & \multicolumn{1}{c}{ SR $^{\text {** }}$} \\
\hline 1 & 19,76 & 17,56 & 0,15 & $\mathbf{6 8 , 1 5}$ & 105,61 \\
2 & 24,53 & 41,95 & $\mathbf{2 7 6 , 7 9}$ & 27,11 & 370,39 \\
3 & 5,82 & 1,61 & 7,81 & $\mathbf{2 , 7 3}$ & 17,97 \\
4 & 0,02 & $\mathbf{1 , 6 1}$ & 3,16 & 0,40 & 5,19 \\
5 & 54,26 & $\mathbf{3 9 7 , 5 6}$ & 52,40 & 28,45 & 532,68 \\
6 & 12,65 & 0,00 & $\mathbf{2 7 , 1 1}$ & 2,73 & 42,48 \\
7 & 0,02 & 3,16 & $\mathbf{9 3 , 1 6}$ & 60,02 & 156,35 \\
8 & 5,23 & $\mathbf{1 6 1 , 2 9}$ & 24,53 & 29,82 & 220,87 \\
9 & 23,29 & $\mathbf{9 5 , 6 3}$ & 27,11 & 0,06 & 146,10 \\
\hline Total & 145,56 & 720,39 & 512,23 & 219,47 & 1597,65 \\
\hline
\end{tabular}

Fonte: Os autores, 2019.

Em relação às questões de petrografia, a maior correlação existente em toda matriz ocorre entre $\phi_{4 ; 5}=-0,6$, representando que a maioria dos estudantes acertou a quinta, mas errou a quarta questão. Em seguida, a correlação entre $\phi_{3 ; 5}=-0,59$, possui, praticamente, a mesma intensidade que o coeficiente anteriormente comentado. As correlações $\phi_{2 ; 3}=0,48$ e $\phi_{2 ; 4}=0,49$ indicam que a maioria dos estudantes acertou a segunda questão, ao passo que, majoritariamente, erraram as questões 3 e 4 . O coeficiente de correlação entre $\phi_{3 ; 4}=0,01$ representa que a maioria dos estudantes errou as questões 3 e 4.

Em relação às questões de mineralogia, observa-se que a maioria das questões possuem correlação negativa, mas de intensidade pequena, enquanto as questões de petrografia possuíam correlação de intensidade moderada e forte. 0 coeficiente que possui maior intensidade é $\phi_{6 ; 8}=-0,24$, quando a maioria dos estudantes acertou a oitava questão, mas errou a sexta. A única correlação positiva foi observada em $\phi_{1 ; 6}=0,1$, com a maioria dos acertos para a primeira questão e maioria de erros para a sexta questão.

Em relação ao padrão de correlação da questão de geomorfologia com os outros dois grupos de questões, percebe-se que os coeficientes de correlação são 


\section{Tusm

ISSN: 1984-6444 | http://dx.doi.org/10.5902/1984644442481

menos intensos quando relacionados à temática de mineralogia $(\phi<|0,15|)$ e mais intensos quando relacionados à temática de petrografia $(\phi>|0,23|)$.

Tabela 3 - Correlação entre questões do instrumento de avaliação de aprendizagem.

\begin{tabular}{|c|c|c|c|c|c|c|c|c|c|}
\hline Itens & (1) & (2) & (3) & (4) & ( 5 ) & (6) & ( 7 ) & (8) & (9) \\
\hline $\begin{array}{l}\text { ( } 1 \text { ) Qual dos minerais abaixo } \\
\text { pode ser considerado como um } \\
\text { "mineral formador de rocha" }\end{array}$ & 1,00 & $-0,28$ & 0,21 & 0,23 & $-0,40$ & 0,10 & $-0,04$ & $-0,14$ & $-0,05$ \\
\hline $\begin{array}{l}\text { ( } 2 \text { ) As areias da praia dão } \\
\text { origem a uma rocha que se } \\
\text { chama? }\end{array}$ & $-0,28$ & 1,00 & 0,48 & 0,49 & $-0,14$ & 0,37 & 0,24 & 0,14 & 0,23 \\
\hline $\begin{array}{l}\text { ( } 3 \text { ) São exemplos de rochas } \\
\text { ígneas: }\end{array}$ & 0,21 & 0,48 & 1,00 & 0,01 & $-0,59$ & $-0,12$ & $-0,26$ & $-0,35$ & $-0,26$ \\
\hline $\begin{array}{l}\text { ( } 4 \text { ) São exemplos de rochas } \\
\text { metamórficas: } \\
\text { ( } 5 \text { ) Alaumas rochas são }\end{array}$ & 0,23 & 0,49 & 0,01 & 1,00 & $-0,60$ & $-0,13$ & $-0,27$ & $-0,36$ & $-0,27$ \\
\hline $\begin{array}{l}\text { originadas pelo material que é } \\
\text { expelido pelos vulcões e que } \\
\text { tem o nome de: }\end{array}$ & $-0,40$ & $-0,14$ & $-0,59$ & $-0,60$ & 1,00 & 0,49 & 0,36 & 0,27 & 0,36 \\
\hline $\begin{array}{l}\text { ( } 6 \text { ) O mineral feldspato é muito } \\
\text { utilizado na indústria. Seu } \\
\text { principal uso é na fabricação de: }\end{array}$ & 0,10 & 0,37 & $-0,12$ & $-0,13$ & 0,49 & 1,00 & $-0,14$ & $-0,24$ & $-0,15$ \\
\hline $\begin{array}{l}\text { ( } 7 \text { ) Dos minerais abaixo, qual é } \\
\text { encontrado em grande } \\
\text { quantidade na natureza? } \\
\text { ( } 8 \text { ) Os minerais micáceos são }\end{array}$ & $-0,04$ & 0,24 & $-0,26$ & $-0,27$ & 0,36 & $-0,14$ & 1,00 & $-0,10$ & 0,00 \\
\hline $\begin{array}{l}\text { muito utilizados na indústria. } \\
\text { Seu principal uso é na } \\
\text { fabricação de: }\end{array}$ & $-0,14$ & 0,14 & $-0,35$ & $-0,36$ & 0,27 & $-0,24$ & $-0,10$ & 1,00 & 0,09 \\
\hline $\begin{array}{l}\text { ( } 9 \text { ) Em qual das rochas abaixo } \\
\text { é mais provável de se encontrar } \\
\text { cavernas? }\end{array}$ & $-0,05$ & 0,23 & $-0,26$ & $-0,27$ & 0,36 & $-0,15$ & 0,00 & 0,09 & 1,00 \\
\hline
\end{tabular}

Fonte: Os autores, 2020.

Em seguida, o tópico de considerações finais apresenta as principais conclusões do estudo, limitações e possibilidades de pesquisas futuras.

\section{Considerações finais ${ }^{2}$}

O desenvolvimento deste trabalho possui relevância por tratar da produção de uma ferramenta acessível, de baixo custo, que facilita a propagação de conhecimento em geociências para as escolas das redes pública e privada da Região Metropolitana de Natal de Ensino Fundamental. São apresentados e 


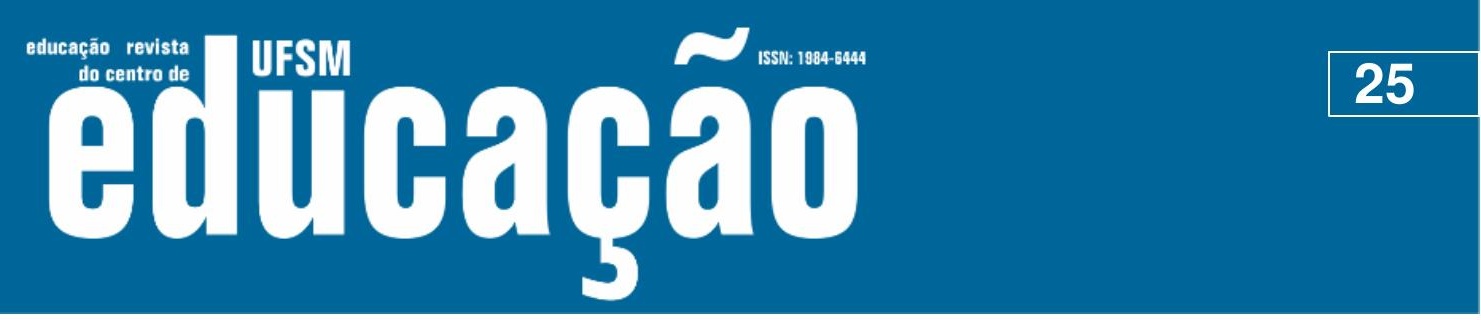

ISSN: 1984-6444 | http://dx.doi.org/10.5902/1984644442481

disseminados conhecimentos das geociências e da geodiversidade do Rio Grande do Norte, concretizando a conexão com a realidade dos alunos com o observado nas diferentes paisagens e situações cotidianas, buscando apresentar os minerais e associá-los com objetos tangíveis do cotidiano.

Com o objetivo de descrever os resultados produzidos pelo projeto de extensão "Uso de Kits de Minerais e Rochas no Auxílio do Ensino de Geociências no Ensino Fundamental", o presente trabalho apresentou o detalhamento da produção dos kits de minerais e rochas e a avaliação de aprendizagem do conteúdo trabalhado na exposição do museu e oficinas com os kits.

Foi possível observar o interesse dos alunos na visita ao museu, assim como pelas atividades de extensão desenvolvidas no ambiente do Museu de Minérios do $\mathrm{RN}$, fator considerado como positivo, pois o local pode ser enxergado como ambiente interdisciplinar favorável ao aprendizado de conteúdos por meio da ludicidade e materiais didáticos interativos.

Também foi verificada, ao longo das oficinas, uma disposição ímpar quando os alunos têm contato com as amostras de minerais e rochas. Com suas diferentes formas geométricas, brilhos e hábitos, os minerais se apresentam para as crianças como algo inusitado e inédito, tal qual aqueles materiais fossem feitos por um "artesão", o que pode ser explicado pela ausência desses elementos naturais no cotidiano das mesmas.

As análises estatísticas apontaram que as questões com maior nível de dificuldade são aquelas com maior nível de tecnicidade e termos não habituais aos alunos de ensino fundamental. O teste de $\chi^{2}$ apontou um padrão de resposta praticamente aleatório para essas questões, as duas tratam sobre rochas ígneas e metamórficas e pedem a memorização dos exemplares e tipologias após 0 , provável, primeiro contato com tais termos.

As análises de correlação, corroboram com os padrões de aleatoriedade, mostrando a maior intensidade de associação entre as questões 3 e 4 com a quinta, quando as duas primeiras são mais acertadas, a última possui maiores níveis de 


\section{Fism Aitlathá

ISSN: 1984-6444 | http://dx.doi.org/10.5902/1984644442481

erro. O desafio, posto também como reflexão, é de aproximar, cada vez mais, essas terminologias das geociências da vida dos alunos.

O estudo corroborou sobre a perspectiva deficitária do ensino de geociências no âmbito educacional brasileiro, mais especificamente do EF. Como visto, no teste de aprendizagem e nas subsequentes análises, os estudantes tiveram pouco ou nenhum contato com os conteúdos básicos sobre minerais, rochas e elementos da geodiversidade, destaca-se aqui a necessidade de aproximar esses conhecimentos no $\mathrm{EF}$, sendo os kits e os museus de geociências importantes ferramentas para consolidar e difundir o aprendizado nesse nível de ensino.

Como limitação da pesquisa, destaca-se que o instrumento de avaliação de aprendizagem possui aspectos que podem ser incrementados para sua aplicação em pesquisas futuras. De modo a aperfeiçoar a identificação do nível de assimilação dos conteúdos de geociências no EF com maior precisão. Além disso, sutilidades teóricas podem indicar subjetividade no caráter da resposta, como mencionadas no capítulo de procedimentos metodológicos, denotando a dificuldade de avaliar o aprendizado das ciências geológicas, por sua característica não-exata, pela complexidade de seus fenômenos e sua compreensão na vivência dos alunos.

Os próximos estudos podem elencar roteiros de aula que se apropriem deste material didático para o ensino fundamental, bem como a pesquisa pode ser estendida para aplicar a metodologia a outros contextos de níveis de ensino e, até mesmo, ser aplicada para a sociedade como forma de divulgar o ensino de geociências e sua importância para o conhecimento dos processos de gênese e transformação da natureza.

\section{Referências}

ALENCAR, Roberta; NASCIMENTO, Rosemy da Silva; GUIMARÃES, Gilson Burigo. Geociências no ensino fundamental: ciências ou geografia? Da história da Terra à paisagem local através da geodiversidade da ilha de Santa Catarina. Simpósio Nacional de Ensino de Ciências e Tecnologias, v. 3, 2012. 


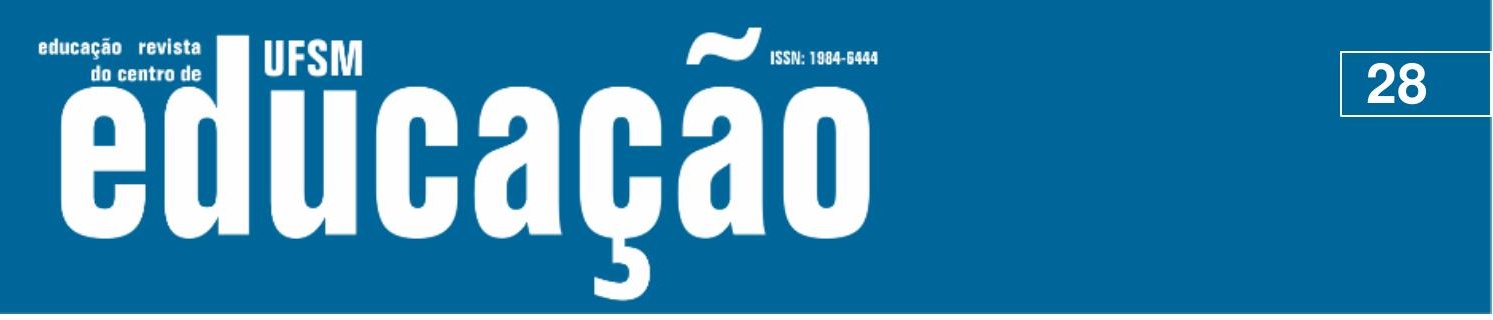

ISSN: 1984-6444 | http://dx.doi.org/10.5902/1984644442481

COSTA, Samara dos Anjos da. O Reconhecimento das Geociências na Educação Básica: Uma proposta de material pedagógico para professores do distrito federal. 2013. TCC (Trabalho de Conclusão de Curso), Faculdade UnB Planaltina, Planaltina-DF, 2013.

ERNESTO, Marcia et al. Perspectivas do ensino de Geociências. Estudos Avançados, v. 32, n. 94, p. 331-343, 2018.

FÁVERO, Luiz Paulo; BELFIORE, Patrícia. Manual de análise de dados: estatística e modelagem multivariada com Excel, SPSS e Stata. Rio de Janeiro: Elsevier, 2017.

FREIRE, Luciana Martins; LIMA, Joselito Santiago de; VERÍSSIMO, Cesar Ulisses Vieira; SILVA, Edson Vicente da. Carste em Rochas Não Carbonáticas: contribuição ao estudo geomorfológico em cavernas de arenito da Amazônia Paraense (Karst in Non-Carbonate Rocks: contribution in geomorphological study in sandstones caves of the Paraense Amazon). Revista Brasileira de Geografia Física, v. 10, n. 6, p. 1829-1845, 2017.

LEINZ Viktor; AMARAL, Sérgio Estanislau do. Geologia geral. 11 ed. São Paulo: Cia. Ed. Nacional. 1989.

LICCARDO, Antonio; GUIMARÃES, Gilson Burigo. Geodiversidade na educação. Ponta Grossa: Estúdio Texto. 2014.

OLIVEIRA, Robson Rafael de; NASCIMENTO, Marcos Antonio Leite do. Mapa geológico simplificado do estado do Rio Grande do Norte: representação cartográfica de elementos geológicos para divulgação das Geociências. Terrae Didatica, v. 15, p. e019003-e019003, 2019.

RYKER, Katherine. An evaluation of classroom practices, inquiry and teaching beliefs in introductory geoscience classrooms. 2014. Disponível em: https://repository.lib.ncsu.edu/bitstream/handle/1840.16/9382/. Acesso em: 04 fev. 2020.

SILVA, Matheus Lisboa Nobre da; NASCIMENTO, Marcos Antonio Leite do. Panorama Geral Sobre a Geoconservação em Natal (RN): Ameaças à Geodiversidade In Situ e Ex Situ. HOLOS, v. 7, p. 3-14, 2016.

STEWART, Ian; LEWIS, Deirdre. Communicating contested geoscience to the public: Moving from 'matters of fact' to 'matters of concern'. Earth-science reviews, v. 174, p. 122-133, 2017.

TEASDALE, Rachel; MARCUM, Bev; HEASTON, Tanya. Teaching rocks and minerals in the hands on lab: A teaching and learning experience for pre-credential undergraduates at CSU Chico. Journal of Geoscience Education, v. 56, n. 5, p. 401-407, 2008.

TEIXEIRA, Wilson; TOLEDO, Maria Cristina Motta de; FAIRCHILD, Thomas R.; TAIOLI, Fabio (org.). Decifrando a Terra. São Paulo: Oficina de Textos, 2003. 


\section{ح

ISSN: 1984-6444 | http://dx.doi.org/10.5902/1984644442481

\section{(c) $(1) \otimes$}

This work is licensed under a Creative Commons Attribution-NonCommercial 4.0 International (CC BY-NC 4.0)

\section{Notas}

\footnotetext{
${ }^{1}$ Elementos abióticos que são transferidos por intervenção antrópica do seu local de formação para outro.

${ }^{2}$ Os autores agradecem à Pró-Reitoria de Extensão do Instituto Federal do Rio Grande do Norte pela concessão de recursos e materiais e à equipe do Museu de Minérios do RN pelo apoio e empenho nas atividades.
} 